Peer-Reviewed Article

ISSN: 2162-3104 Print/ ISSN: 2166-3750 Online Volume 7, Issue 4 (2017), pp. 1096-1103 (C) Journal of International Students http://jistudents.org/ doi: $10.5281 /$ zenodo. 1035971

\title{
Peer Support for International Doctoral Students in Managing Supervision Relationships
}

\author{
Sherrie Lee \\ University of Waikato, New Zealand
}

\begin{abstract}
Doctoral education is based on a pedagogical model of apprenticeship where the expert, the more experienced academic, advises or mentors the student. Scholars have recognized the challenges of doctoral supervision due to the intense and individualized nature of the relationship. Based on the author's personal experiences as a doctoral student and a student advocate at a university in New Zealand, this article highlights the challenges that international doctoral students face with regard to navigating the supervision relationship. The article discusses how student advocacy and peer support played an important role in resolving issues. The article concludes that peer networks are important resources for international doctoral students to make informed decisions regarding complex issues related to doctoral supervision.
\end{abstract}

Keywords: doctoral supervision relationships, international students, peer support, student advocacy

Doctoral education has traditionally been based on a pedagogy of apprenticeship where there is a private and individualized working relationship between the expert academic and the novice student (Grant, 2003; Johnson, Lee, \& Green, 2000; Walker, 2008). Although there are shifts in how doctoral education is practiced, such as facilitating collaborative research environments (e.g., Malfroy, 2005), the traditional 
apprenticeship relationship remains a central experience to doctoral study (Walker, 2008). In universities in North America, the relationship is between the student and a doctoral advisory committee of typically four or more faculty members, whereas in universities elsewhere such as Australia and New Zealand, the committee is referred to as a panel of supervisors, typically two or three, and in some cases, there may be just one supervisor. This article is based in an Australasian context and refers to this apprenticeship relationship as supervision.

The supervision relationship has been recognized as problematic due to its "peculiarly intense and negotiated character" (Grant, 2003, p. 175). The relationship is intense as the student's primary source of guidance comes from the same expert(s) for a period of three or more years (three years being the expected timeframe for completion). Supervision meetings are often conducted "behind closed doors ... [where] the intensity of the interpersonal relations ... is presumed but uninterrogated" (McWilliam \& Palmer, 1995, p. 32). It is also a relationship which is constantly being negotiated and where the student is expected to transform from a novice to an independent researcher (Grant, 2003). The supervision relationship is thereby fraught with unequal power and social dynamics between the supervisor and student. International doctoral students not only have to navigate a challenging relationship, but also face additional sociocultural concerns such as unfamiliar academic, linguistic, and cultural environments (Wang \& $\mathrm{Li}, 2011$ ) and challenges in forging new social relationships and networks (Deem \& Brehony, 2000; Trice, 2004).

Based on the author's personal experiences as a doctoral student and student advocate at a New Zealand university, the remainder of the article highlights the challenges of managing supervision relationships for international students and discusses how issues were addressed through peer support. Peer support refers to the provision of help from one to another on the basis of similar status and shared experiences (Boud, Cohen, \& Sampson, 2001). While the report of personal experiences does not constitute formal research, scholars such as Wilkins (1993) have recognized the importance of autobiographical experiences as important sources of sociological insight. In writing autobiographically, however, there is a need to consider ethical responsibilities to those who may be identified or implicated (Ellis, 2007). To this end, I am conscious not to reveal information or identities of particular persons but instead, draw attention to the issues and discuss how they were addressed. 


\section{BACKGROUND}

I am an international student from Singapore and am currently in my third year of doctoral study at a university in New Zealand. In my first year, I joined the Postgraduate Students' Association (PGSA), a student-led organization affiliated with the students' union at the university. The overarching mission of the PGSA is to represent all postgraduate students (domestic and international students), who range from those pursuing qualifications just above Bachelor's level to doctoral students, in matters pertinent to the postgraduate experience. When I first joined the PGSA, I was elected its Secretary as part of its executive committee. In the following year, I was elected President; in that capacity, I was also the postgraduate student representative on university committees.

While the majority of the PGSA activities are social or networking events, an important mission of the PGSA is to protect the interests and well-being of postgraduate students. This advocacy role involves providing opportunities for postgraduate students to share their concerns and engaging appropriate stakeholders to address the issues. In my leadership role in the PGSA, I regularly interacted on an informal basis with postgraduate students, and in particular, international doctoral students. Based on my experiences as a PGSA representative, I share how peer support benefitted international doctoral students in navigating their supervision relationships in terms of: (1) having an avenue to voice concerns; (2) understanding how to communicate with supervisors; and (3) getting personal guidance with difficult situations.

\section{HAVING AN AVENUE TO VOICE CONCERNS}

The PGSA holds monthly meetings where members have the opportunity to meet the executive committee members, as well as raise any concerns that they might have. There were several occasions where students attended the meeting to share particular issues they faced, or communicated with executive committee members what they wished to be brought up at the meeting.

For international postgraduate students who had limited social networks in a new country, the PGSA meetings provided them a congenial space to discuss their concerns. International students raised matters such as visa and financial related regulations, as well as funding and scholarship 
opportunities. At times, students brought up issues that they could not resolve directly with their supervisors. For example, one student brought up that he was unable to proceed with his original research plan as there was a sudden reduction in funding. He and his supervisors had different responses to the situation; while his supervisors saw this as a matter of changing the scope of the research, the student felt that it was more important to secure the necessary funding for the original research. Another student raised the issue of not being consulted regarding a change in his supervisors; furthermore, he was concerned that these changes would affect his scholarship from his home government.

In response to such student concerns, as the PGSA representative, I facilitated direct communication between the student and the appropriate staff members, or requested a written or formal response from the university department that could then be shared with the student and other interested parties. The latter approach was particularly effective when students requested anonymity or did not want to engage directly with the university.

\section{UNDERSTANDING HOW TO COMMUNICATE WITH SUPERVISORS}

While it was useful to have the opportunity to raise issues at PGSA meetings, there were times when it was more appropriate to seek advice within a private conversation, such as when dealing with interpersonal issues. One of the common challenges for international students is to adjust to an unfamiliar culture (Hechanova-Alampay, Beehr, Christiansen, \& Van Horn, 2002; Major, 2005; Sherry, Thomas, \& Chui, 2010). Within the context of a supervision relationship, there are also individual personalities of supervisors to become accustomed to, and more importantly, students need to be able to relate to supervisors personally and professionally, especially when their relationship is over the period of several years.

From my personal experience, I have found that one common way for international students to understand the social dynamics of supervision relationships is to ask other doctoral students, often fellow international students, and where possible, those from the same countries or similar cultural backgrounds. Because supervision relationships take place in private spaces, it is from the experiences of other students' supervision relationships that new students can make sense for themselves of what to expect. The preference for seeking advice from an international or co- 
national student is likely because they too started from similar position of understanding a new culture.

For example, an international student approached me with the issue of not receiving a response from her supervisors. She had sent an email to her supervisors several weeks prior and was anxious in receiving feedback on a particular piece of writing she had submitted. She revealed that her supervisors were always very busy and she was feeling frustrated at not getting prompt attention.

In response, I first explained that I too faced similar issues in the initial period of my doctoral studies. Then I asked her to consider what other commitments her supervisors had, for example, teaching, marking students' assignments, and being away for conferences. I also suggested that in requesting some action from supervisors, it was useful to indicate when she expected to received feedback by. We then discussed how best to phrase the wording of the email message. I further suggested that she could think of other things she could do while waiting for her supervisors to respond, for example, working on other pieces of writing or organizing her research notes. At the end of conversation, she felt she was more aware of how to communicate with her supervisors and better manage her expectations of them.

\section{GETTING PERSONAL GUIDANCE WITH DIFFICULT ISSUES}

Apart from potential communication issues with supervisors, there can be other more difficult issues with supervision relationships such as prolonged delays in scheduling meetings, not receiving the desired feedback from supervisors, and disagreements over the direction of one's research. Regardless of whether the supervisors, students, or external factors contributed to the situation, it is ultimately the student who bears the burden of overcoming these issues.

International students often have a strict timeframe to complete their doctoral study. For example, some may be on a three-year scholarship from their government. More generally, all international students will have to complete their study within the time period of their student visas. Although students may request to extend their period of study, doing so incurs other costs, and is undesirable in most cases. For scholarship holders, not only will their funds run out, but they may also have to pay back their governments for delaying their completion. Self-funded students may have only budgeted enough for what they anticipated was a three-year program 
and securing additional funding may mean finding work in an already tight labor market.

However, there may not be a straightforward solution to resolving difficult issues. At times, it might be difficult to assess whether a delay is temporary or a more serious issue where external intervention is necessary. In complex situations, students may hesitate to take action if it threatens to disrupt the supervision relationship and cause either party to lose "face," that is, to be embarrassed or humiliated (Ingleton \& Cadman, 2002). In addition, there may be the risk of further delay if attempts to resolve current issues become protracted. Such unresolved tensions invariably affect students' mental health negatively (Levecque, Anseel, De Beuckelaer, Van der Heyden, \& Gisle, 2017).

In such situations, student advocates are important resources to help guide students to locate appropriate resources and to provide necessary support. In my leadership role, I was well acquainted with the various postgraduate-related departments and their functions, and was able to offer suggestions to students as to the appropriate people or departments to approach. In one particular instance, a student was overwhelmed by the situation she was facing and was not sure who she should approach to have her issues resolved. I first shared with her the roles of the different departments and how they related to her particular situation. When she expressed hesitation at having to attend multiple meetings, I shared with her that it was acceptable for her to bring along a support when going for these meetings, and offered to attend these meetings with her. Before going to the meetings, we also discussed possible scenarios that would arise from the meetings to help her mentally prepare for the final outcome.

\section{CONCLUSION}

Entering a doctoral supervision relationship is a challenging endeavor. Supervision relationship issues are often delicate matters. For international doctoral students, constraints in funding and completion timeframes add to the challenges of navigating supervision relationships. In this autobiographical reflection, I have highlighted how the PGSA plays an important role in offering peer support to international doctoral students. As a student-led organization, the PGSA provides a platform for fellow postgraduate students to voice their concerns. Such a platform is valuable for international students in particular because of their relatively weaker social networks in a new country. In my leadership capacity and as an 
international student, I was able to provide personalized guidance to other international students, particularly those in trying circumstances, and assist them in making informed decisions.

Peer support networks are therefore important resources for international doctoral students in understanding the nature of supervision relationships in a new social and cultural context. It is hoped that universities will work alongside student groups and advocates to better meet the particular needs of international doctoral students. For example, university budgets can allocate funding to support social and professional development events that allow international students to establish support networks. Furthermore, student affairs and similar departments can coorganize such events with student groups so that university representatives themselves become more familiar with the needs of this particular group of students. Finally, universities can help hone the leadership and organizational skills of student groups and advocates by providing relevant training, especially to new student leaders, thus also helping to ensure the continuity of student organizations.

\section{REFERENCES}

Boud, D., Cohen, R., \& Sampson, J. (Eds.). (2001). Peer learning in higher education: Learning from and with each other. Abingdon, England: Routledge.

Deem, R., \& Brehony, K. J. (2000). Doctoral students' access to research culturesare some more unequal than others? Studies in Higher Education, 25(2), 149-165. doi:10.1080/713696138

Ellis, C. (2007). Telling secrets, revealing Lives: Relational ethics in research with intimate others. Qualitative Inquiry, 13(1), 3-29. doi: $10.1177 / 1077800406294947$

Grant, B. (2003). Mapping the pleasures and risks of supervision. Discourse: Studies in the Cultural Politics of Education, 24(2), 175-190. doi: $10.1080 / 01596300303042$

Harman, G. (2003). International PhD students in Australian universities: Financial support, course experience and career plans. International Journal of Educational Development, 23(3), 339-351. doi:10.1016/S07380593(02)00054-8

Hechanova-Alampay, R., Beehr, T. A., Christiansen, N. D., \& Van Horn, K. R. (2002). Adjustment and strain among domestic and international student sojourners: A longitudinal study. School Psychology International, 23(4), 458-474. 
Ingleton, C., \& Cadman, K. (2002). Silent issues for international postgraduate research students: Emotion and agency in academic success. The Australian Educational Researcher, 29, 93-113. doi:10.1007/BF03219771

Johnson, L., Lee, A., \& Green, B. (2000). The PhD and the autonomous self: Gender, rationality and postgraduate pedagogy. Studies in Higher Education, 25(2), 135-147. doi:10.1080/713696141

Levecque, K., Anseel, F., De Beuckelaer, A., Van der Heyden, J., \& Gisle, L. (2017). Work organization and mental health problems in $\mathrm{PhD}$ students. Research Policy, 46(4), 868-879. doi:10.1016/j.respol.2017.02.008

Major, E. M. (2005). Co-national support, cultural therapy, and the adjustment of Asian students to an English-speaking university culture. International Education Journal, 6(1), 84-95.

Malfroy, J. (2005). Doctoral supervision, workplace research and changing pedagogic practices. Higher Education Research \& Development, 24(2), 165-178. doi:10.1080/07294360500062961

McWilliam, E., \& Palmer, P. (1995). Teaching tech(no)bodies: Open learning and postgraduate pedagogy. Australian Universities Review, 38, 32-34. Retrieved from http://www.aur.org.au/archive/38-02/aur_3802.pdf\#page $=33$

Sherry, M., Thomas, P., \& Chui, W. H. (2010). International students: A vulnerable student population. Higher Education, 60(1), 33-46. http://doi.org/10.1007/s10734-009-9284-z

Trice, A. G. (2004). Mixing it up: International graduate students' social interactions with American students. Journal of College Student Development, 45(6), 671-687. doi:10.1353/csd.2004.0074

Walker, G. E. (2008). The formation of scholars: Rethinking doctoral education for the twenty-first century. San Francisco, CA: Jossey-Bass.

Wang, T., \& Li, L. Y. (2011). "Tell me what to do" vs. "guide me through it": Feedback experiences of international doctoral students. Active Learning in Higher Education, 12(2), 101-112. doi:10.1177/1469787411402438

Wilkins, R. (1993). Taking it personally: A note on emotion and autobiography. Sociology, 27(1), 93-100.

SHERRIE LEE is a PhD candidate at the University of Waikato. Her doctoral research uses the concept of brokering to explore how international students at a New Zealand university seek help with their academic learning from peers and significant others. Email: leesherrie@gmail.com 